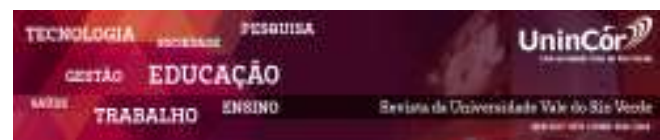

Revista da Universidade Vale do Rio Verde ISSN: 1517-0276 / EISSN: 2236-5362 v. $17 \mid$ n. 1 | Ano 2019

Magali Aparecida Alves de Moraes Faculdade de Medicina de Marília - Famema, dmagalimoraes@hotmail.com

Maria Cristina Guimaraes da Costa Faculdade de Medicina de Marília - Famema, mcgcosta60@gmail.com

Luzmarina Aparecida Doretto Braccialli Faculdade de Medicina de Marília - Famema, luzbra@terra.com.br

Cleber José Mazzoni

Faculdade de Medicina de Marília - Famema, cjm@unimedmarilia.com.br

\section{AVALIAÇÃO DOS RECURSOS AFETIVOS: PERCEPÇÃO DE PROFESSORES E DE ESTUDANTES}

\section{RESUMO}

Em currículos orientados por competência, a avaliação dos estudantes envolve os recursos cognitivos, psicomotores e afetivos, porém a avaliação dos primeiros se encontra mais compreendida e estruturada do que a do último. O objetivo deste estudo foi analisar a percepção de professores e estudantes quanto à avaliação dos recursos afetivos no processo ensinoaprendizagem durante o exercício de avaliação da prática profissional. Trata-se de um estudo qualitativo que utilizou entrevistas com professores e estudantes dos cursos de medicina e enfermagem. Realizou-se a análise de conteúdo, identificando-se duas temáticas: 1) Compreensão do conceito de recursos afetivos por estudantes e professores e, 2) Avaliação dos recursos afetivos no cenário simulado da prática profissional. Estudantes e professores utilizaram para conceituar os recursos afetivos, exemplos com aspectos de comunicação, relação e comportamento valorizando-os para a formação de médicos e enfermeiros. Reconheceram que existem critérios para avaliar os recursos afetivos nos formatos de avaliação existentes, porém, sugerem que sejam mais claros. A pesquisa mostrou também que avaliar a atitude pode ser uma maneira mais objetiva na avaliação dos recursos afetivos.

Palavras-chave: Atitude. Avaliação. Educação. Educação médica. Educação em enfermagem.

\section{EVALUATION OF THE AFFECTIVE DOMAIN: TEACHERS AND STUDENTS PERCEPTIONS}


Keywords: Attitude. Evaluation. Education. Education medical. Education nursing.

Recebido em: 09/08/2018 - Aprovado em: 05/04/2019 - Disponibilizado em: 15/07/2019

\section{INTRODUÇÃO}

A Faculdade de Medicina de Marília (Famema), desde 2003, adota o currículo integrado e orientado por competência, entendida essa proposta como a capacidade de mobilizar articuladamente diferentes recursos - cognitivos, afetivos e psicomotores - que, combinados, permitem abordar/resolver, de distintas maneiras, novas situações referentes à prática profissional (FAMEMA, 2015).

Nesse currículo, a avaliação é significativa e norteadora de todo o processo de ensino e aprendizagem sendo baseada em resultados observáveis, ou seja, os desempenhos que se compõem de atributos a serem desenvolvidos ao longo do curso.

Uma das formas de avaliação proposta é o Exercício de Avaliação da Prática Profissional (EAPP), estratégia que constitui situações simuladas, relacionadas ao cuidado individual, situações do cuidado coletivo e organização do processo de trabalho em saúde, nas quais o estudante realiza as ações e é avaliado de acordo com o desempenho esperado para a série (COSTA et al. 2011). Nessa modalidade, faz-se presente a avaliação dos recursos cognitivos, psicomotores e afetivos. Observa-se, porém, que as primeiras se encontram mais compreendidas e estruturadas do que a afetiva. Autores conceituam os aspectos correlacionados às habilidades afetivas como sendo
[...] uma variedade de sentimentos, uma emoção ou um grau de aceitação ou de rejeição. O domínio afetivo varia desde a atenção simples a fenômenos selecionados, até qualidades de caráter e de consciência complexas, mas internamente consciente (SANTIAGO; CARVALHO, 2006, p. 293).

As habilidades afetivas são compreendidas como um contínuo que se desenvolve a partir do momento em que o indivíduo toma consciência de um fenômeno e

[...] passa a responder ao
fenômeno com um
interesse positivo,
acompanhado por um
sentimento de satisfação,
prazer ou consentimento
[...] e adquire uma crença
e um valor sobre o
mesmo. (SANTIAGO;
CARVALHO, 2006, p.
293).

A partir de então, ele age porque "se sente comprometido com o valor que inspira o comportamento". Em várias situações da vida, os valores podem entrar em conflito ou cooperação exigindo que os indivíduos criem normas internas para manejar tais sentimentos. Finalmente, uma vez tendo o valor "organizado e integrado com uma filosofia de vida, o comportamento torna-se consciente, coerente e afetivamente maduro."

(SANTIAGO; CARVALHO, 2006, p. 293).

Dentre os recursos afetivos, as atitudes são objeto de estudo da Psicologia Social e são 
conceituadas de várias maneiras. Uma delas conceitua atitude como "uma maneira organizada e coerente de pensar, sentir e reagir em relação a pessoas, grupos sociais ou, mais genericamente, a qualquer acontecimento ocorrido no meio circulante.” (COLARES et al., 2002, p.195).

Outro conceito relativo à atitude é o de “[...] uma organização duradoura dotada de carga afetiva pró ou contra o objeto social definido, que predispõe a uma ação coerente com as cognições e afetos relativos a esse objeto." (TRONCON et al., 2003, p. 21).

$\mathrm{Na}$ educação médica, são reconhecidas a necessidade e a importância de o estudante incorporar atitudes positivas ou construtivas. Entretanto, a avaliação de atitudes, junto com outras habilidades afetivas, tem sido considerada uma área de grande dificuldade na avaliação educacional. (COLARES et al., 2002).

Sendo assim, as atitudes dos estudantes, no campo da educação, têm relevância especial dada a existência de uma relação definida entre atitudes e aprendizagem. (TRONCON et al., 2003).

O currículo integrado e orientado por competência profissional adotado pela Famema e a aplicação de metodologias ativas de ensinoaprendizagem exigiram mudanças nas avaliações para além das avaliações cognitivas e psicomotoras já que, nas atividades profissionais, também permeiam os recursos afetivos. Nessa perspectiva questiona-se: como professores e estudantes compreendem ou conceituam recursos afetivos? Os professores têm propriedade dos critérios utilizados para a avaliação dos recursos afetivos? Os estudantes consideram-se avaliados em seus recursos afetivos e se autoavaliam?
Considerando esses questionamentos e a proposta curricular da Famema, faz-se necessário um estudo no que se refere à avaliação dos recursos afetivos.

Os resultados desta pesquisa poderão contribuir para o aperfeiçoamento dos critérios para avaliação de atitudes dos estudantes, bem como, para o investimento em capacitação dos professores. Para tanto tem-se como objetivo analisar a percepção dos professores e estudantes quanto à avaliação dos recursos afetivos no processo ensino-aprendizagem da prática profissional durante os EAPP.

\section{MÉTODO}

Esta pesquisa foi desenvolvida por meio de estudo qualitativo, que guarda maior capacidade em analisar significados e percepções. $\mathrm{O}$ estudo iniciou-se após a aprovação do Comitê de Ética em Pesquisa Envolvendo Seres Humanos da Famema, sob o protocolo de número 588/12.

Para a coleta de dados, utilizamos entrevistas semiestruturadas com 25 professores de ambos os cursos e 15 estudantes da $1^{\mathrm{a}}$ a $4^{\mathrm{a}}$ e da $6^{\mathrm{a}}$ série do Curso de Medicina e 9 estudantes da $1^{\mathrm{a}}$ a $4^{\mathrm{a}}$ série do Curso de Enfermagem da Famema que participaram do EAPP. Foi utilizado para o término das entrevistas o critério de saturação por questão.

Para a seleção dos professores, utilizamos, como critério de inclusão, experiência no Laboratório de Prática Profissional (LPP) ou, pelo menos, cinco anos de experiência com o EAPP.

O LPP é um Laboratório de prática simulada, com atividades em pequenos grupos de 
estudantes. Os encontros acontecem durante o ano letivo, com lógica formativa e se constituem em dois momentos: o primeiro é um exercício de avaliação da prática profissional simulada e o segundo, denominado de apoio, em que se discutem as dúvidas, o resultado da busca de informações e o treinamento de exame clínico. (COSTA et al., 2011; MORAES et al., 2012).

A seleção dos estudantes foi feita de forma aleatória, utilizando-se a lista de presença e o aceite para participar. As entrevistas foram registradas por gravador de voz, após o consentimento dos participantes, e transcritas na íntegra para serem melhor exploradas no procedimento de análise. Para garantir o sigilo delas, utilizamos código alfanumérico, sendo $\mathrm{P}$ para professores e E para estudantes, discriminando a sequência e a série em que se encontravam os sujeitos.

Os dados obtidos foram submetidos ao método de análise de conteúdo, modalidade temática. (GOMES, 2016).

\section{RESULTADOS E DISCUSSÃO}

Elegemos duas temáticas após a análise das entrevistas, sendo elas:

\section{1) Compreensão do conceito de recursos} afetivos por estudantes e professores

Uma forma de avaliar os recursos afetivos é a observação direta das atitudes, como elemento concreto e possível de ser observado em um campo de muita subjetividade, por elas expressarem em cada desempenho a concretização dos recursos afetivos.
$\mathrm{Na}$ análise das falas dos estudantes e professores, mesmo com a dificuldade na interpretação dos recursos afetivos, pudemos observar que eles apresentam uma noção global do conceito. Eles utilizaram para conceituar exemplos com aspectos de comunicação, de relação e de comportamento.

Quanto aos aspectos da relação, os estudantes consideram o relacionamento interpessoal entre pacientes, profissionais, grupos de estudantes e professores, caracterizando-os como saber lidar com o outro e consigo próprio, relação de confiança, vínculo, reconhecimento dos sentimentos e emoções envolvidos na relação, respeito, afeto na relação com o paciente e a investigação do seu aspecto psicológico: "[...] saber lidar com as situações, saber lidar com os seus sentimentos e com os sentimentos do outro e saber como gerenciar isso" (EE21).

Os estudantes evidenciaram a comunicação e destacaram o saber ouvir: "[...] o que você tenta falar, as dúvidas dele, você construir um vínculo [...] (EE41). [...] as suas reações verbais e não verbais" (EE13).

Estudos apontam que a comunicação é algo que pode ser aprendida, sentida e vivenciada, ou seja, pela identificação de nossas próprias emoções e sentimentos e de outras pessoas, na vida profissional e pessoal. Reforçam os autores que essas reflexões possibilitam a tomada de consciência para mudança de atitudes (BRAGA; SILVA, 2010). Outro aspecto de entendimento sobre o recurso afetivo diz respeito ao comportamento do estudante, expressado como modo de agir, reação frente a uma situação inesperada, postura ética e profissional, não 
julgar o paciente, manter privacidade e garantir sigilo: "[...] como você se comporta na frente dele, se é empático, se o acolhe [...] (EM32). [...] se tenho uma postura ética e profissional" (EM11).

$\mathrm{Na}$ visão dos professores, além dos aspectos anteriormente referidos pelos estudantes, a relação inclui o relacionamento interpessoal com a equipe. Também apontam a manifestação das características pessoais na relação, aspectos constitucionais (recursos internos) e aprendidos para lidar na relação com o paciente, como se sentem diante desse e com o que recebem do outro, o envolvimento com o outro em cuidar, sentimentos, juízo de valores, cometimento, responsabilização, respeito, consideração com o outro como sujeito com suas crenças, valores e cultura, vínculo e compreensão com a angústia do paciente.

Ressaltam, ainda, que, para lidar com o outro, é necessário desenvolver a empatia, a comunicação, a compreensão, a solidariedade e a resiliência.

[...] é o que o aluno vem trazendo dentro da personalidade dele. Aquelas habilidades, aqueles recursos que ele tem para lidar com outro ser humano, que é a questão de empatia, compreensão, comunicação, compaixão, solidariedade, delicadeza,fineza,

humildade para poder aceitar o outro do jeito que ele é, resiliência [...] ser uma pessoa mais polida, menos orgulhosa, menos vaidosa (P24).

O professor destaca claramente o valor da empatia na formação do profissional da saúde. Suartz et al. (2013) reforçam que a empatia pode ser aprendida e está vinculada com a melhora da competência profissional.

Ainda em relação aos aspectos da comunicação, ficaram evidentes a necessidade da clareza na linguagem, o saber ouvir e responder, a escuta ampliada, a postura corporal, o tom de voz, o olhar, a forma de falar, a forma coerente e integral de abordar o paciente e orientá-lo: "[...] a postura que ele tem de escuta ampliada [...]. Uma linguagem sem muitas gírias, com um português correto" (P6).

Quanto ao comportamento, os professores $\mathrm{P} 1$ e $\mathrm{P} 3$ o relacionaram com a forma que o estudante age diante do paciente e da situação vivenciada, com uma postura respeitosa e demonstrando saber trabalhar em equipe. Referem ainda, que as características pessoais podem interferir nesse modo de agir.

Outros consideram, no comportamento, a ética, a atitude, a postura, a assiduidade, a pontualidade, o interesse e a responsabilidade (P7). Também reforçam a questão ética, tendo em vista o modo como o estudante se comporta e demonstra a afetividade com o paciente (P18).

A relação entre educação ética e emocional tem sido objeto de reflexões, embora, por muito tempo, as emoções não tenham sido valorizadas pela ética. Hoje discutir a ética com os estudantes é mais necessário e difícil, porque as mudanças sociais e tecnológicas são rápidas e as mudanças éticas/morais são mais lentas (DE MARCO et al. 2013).

Outro conceito envolve o aspecto emocional: "[...] tem hora que ele [estudante] fica com raiva e o que a gente faz com isso? Tem hora que ele se emociona a ponto de chorar diante da história." (P6). 
É importante o suporte que o professor possa dar aos estudantes, diante de suas emoções na relação com os pacientes, acolhendo essas emoções, refletindo sobre elas, para poder intervir (DE MARCO et al. 2013).

$\mathrm{O}$ professor (P6) reconhece a importância das emoções dos estudantes, mas não se sente preparado para lidar com elas. Assim, solicita que, nos formatos de avaliação, os critérios estejam mais explícitos.

Outro aspecto importante é o feedback do professor ao estudante, que deve contribuir no difícil percurso entre a teoria e a prática.

Como destacado anteriormente, o universo que compõe os recursos afetivos é complexo, subjetivo e, portanto, difícil de ser avaliado com olhar amplo, com todos os componentes referidos por estudantes, por professores e pela literatura. Mesmo assim, podemos observar, tanto na fala dos alunos quanto na dos professores, a manifestação intuitiva do conceito de recursos afetivos, com exemplos próximos ao conceito utilizado nesse estudo.

Diante do entendimento do conceito dos recursos afetivos, alguns estudantes sugerem que, nos documentos institucionais, os desempenhos relacionados a esses recursos estejam descritos de forma mais clara para facilitar o desenvolvimento e a sua avaliação.

$\mathrm{Na}$ visão do $\mathrm{P} 1$, existe dificuldade dos colegas para entender os recursos afetivos. $\mathrm{O}$ professor P13 acrescenta a necessidade de haver espaços de discussão sobre os recursos afetivos para clarificar esse conceito, porque "[...] às vezes a gente pode confundir [...] e não fazer de maneira correta [a avaliação]".
Essas necessidades apontadas pelos estudantes e professores indicam a valorização desses recursos para a formação de médicos e enfermeiros e poderão facilitar aos envolvidos a avaliação de algo que ainda é muito subjetivo aos entrevistados.

\section{2) Avaliação dos recursos afetivos no cenário simulado da prática profissional}

Esta temática se compõe dos seguintes subtemas: autoavaliação do estudante; percepção do estudante em relação à avaliação realizada pelo professor; autoavaliação do professor e critérios de avaliação nas escalas de desempenho.

\section{Autoavaliação do estudante}

$\mathrm{O}$ estudante posiciona-se, quanto à autoavaliação dos recursos afetivos, como algo difícil de perceber e fazer. Não se sente preparado para sua realização e necessita de modelos, como a do professor (EM33), que nem sempre cobra isso dele (EM41).

$\mathrm{O}$ aprimoramento do processo de ensino e aprendizagem, em relação ao ensino da ética na área da saúde, implica mudanças na organização curricular, no método de ensino e tem o professor como modelo de profissional a ser formado. (CARNEIRO et al., 2010).

A relação professor/estudante deve servir "como modelo de uma relação viva e autêntica [...] em que as atitudes do professor proporcionem continência, acolhimento" e favoreça a elaboração de angústias que surgem diante das experiências desenvolvidas na graduação. (DE MARCO et al. 2013, p. 688).

A autoavaliação fica evidente na questão técnica no que se refere à anamnese, ao exame 
físico e à abordagem biológica. Algumas vezes, faz-se a autoavaliação dos recursos afetivos quando o professor toca no assunto, referindo-se ao acolhimento e indagando se os alunos têm ciência dos cuidados prestados: "[...] a gente acaba deixando de lado. [...] quando o professor toca nesse assunto, a gente revê e revela o que achou sobre isso [...]" (EE41).

Outros avaliam como foi feita a abordagem, relatando se o paciente colaborou ou não, e quais dificuldades teve ao realizar a tarefa (EM22). Alguns salientam, ainda, o contato visual, a comunicação e a atenção à pessoa (EM21).

Um dos estudantes considera difícil realizar a autoavaliação dos recursos afetivos porque essa é feita quando há sentimento de revolta, de nervosismo, mas, segundo ele, isso é difícil de acontecer (EM61). Outros a realizam quando são instigados emocionalmente por uma situação especial: "Com exceção desse caso do cadeirante, que foi uma coisa diferente, que eu não estava esperando [...]" (EM22).

Outro não faz a autoavaliação, referindo que é complicada e por não se sentir à vontade para falar sobre emoções. Faz essa revelação no portfólio da Unidade de Prática Profissional UPP (EE22).

Nesse sentido, a autoavaliação, no que se refere aos recursos afetivos, tem limites e dificuldades. Podemos dizer que a valorização deste aspecto ainda não está internalizada pelos envolvidos. Como a avaliação dos recursos afetivos é complexa e subjetiva devemos realizála considerando a autoavaliação, a avaliação entre pares e a do professor, melhorando sua efetividade. (PAPINCZAK et al., 2007).

\section{Percepção do estudante em relação à avaliação realizada pelo professor}

O estudante considera que há diversos olhares da avaliação nos diferentes anos e entre os professores. Na percepção dos estudantes, o valor que é dado aos recursos afetivos vai diminuindo progressivamente nas séries: "[...] as avaliações se tornam menores com o passar dos anos, [...] volta-se mais para o conhecimento teórico prático e menos para o afetivo." (EM61).

Alguns estudantes consideram que a presença do professor da área de comunicação facilita essa avaliação: "No LPP, tem um profissional de comunicação e aí ele avalia como foi a relação com o paciente, como foi a sua linguagem [...]" (EM32).

Esta fala pode ser justificada porque no LPP se estimula que os recursos afetivos sejam avaliados.

Os estudantes também relatam que a avaliação dos recursos afetivos depende do rigor do professor em apontar as fragilidades do desempenho: "[...] os avaliadores não são todos iguais, um é mais rigoroso e outro é menos [...]" (EM43).

Os estudantes exemplificam os aspectos dos recursos afetivos pelos quais se sentem avaliados, como a sua atuação, o nervosismo, a comunicação e a relação interpessoal, considerando-os positivos para sua formação (EM42, EM62). Entretanto, reiteram a heterogeneidade dos professores na avaliação e a necessidade de maior clareza em seus critérios (EM63). 


\section{Autoavaliação do professor}

Os professores reconhecem que sentem dificuldade para avaliar os recursos afetivos dos estudantes. A subjetividade do tema gera insegurança, porque envolve a história de vida dos estudantes, dificuldade de fazer críticas ou identificar o desvio de caráter desses e orientálos. Outros se sentem desmotivados na avaliação dos recursos afetivos quando percebem que o estudante realiza a tarefa apenas para "agradar" o professor. Por mais que pontue, mostre, parece que faz aquilo para ser aprovado (P8).

Os professores da área de saúde mental referem que se sentem habilitados a avaliar o recurso afetivo pela sua formação e não necessariamente por terem sido capacitados pela instituição (P1, P3 e P23): "[...] como eu tenho uma trajetória [saúde mental], o foco maior é olhar para isto. Então ajuda, mas não significa que eu estou totalmente preparada [...]" (P23).

O professor que não é da área da saúde mental não se sente habilitado para avaliar os recursos afetivos, pois considera, como critério, aspectos psíquicos e emocionais: [...] o aluno que traz um diagnóstico de saúde mental ou uma questão de caráter [...] Como se lida com o estudante que não aceita, que coloca no outro o problema? (P22).

Nesta situação percebemos que o enfoque na saúde mental do estudante é um campo de avaliação complexo, que requer atenção especializada. O avaliador deve perceber alterações neste nível, porém, não cabe a ele identificar quais as possíveis condições psicopatológicas e encaminhá-lo ao profissional especializado. $\mathrm{O}$ avaliador deve observar alterações na atitude do estudante relacionadas à responsabilidade, à ética, à cultura e aos valores.
Pelo fato de o professor entender que a avaliação dos recursos afetivos se refere, exclusivamente, aos aspectos psíquicos e emocionais dos estudantes, o mesmo se isenta de realizar a avaliação por julgar-se não capacitado.

Quanto ao aspecto citado anteriormente, a dificuldade do professor em fazer críticas (P10) acrescenta a necessidade de mais capacitação, referindo que precisamos nos "[...] instrumentalizar, cada vez mais encontramos estudante que não tem capacidade de receber crítica, e nem de se colocar como uma pessoa no processo".

Os métodos ativos de ensino e aprendizagem requerem novas formas de avaliar. A imaturidade dos estudantes é fator que, também pode dificultar o recebimento de críticas realizadas pelo professor (OLIVEIRA; BATISTA, 2012).

Outro professor reconhece que, apesar de os critérios estarem no caderno da sua série, não os segue "de forma bem sistematizada [...] continuo fazendo como sempre fazia, eu acho que neste caso está ainda frágil [...]" (P7).

Entendemos que estabelecer critérios claros sobre a avaliação de recursos afetivos não garante que o professor irá utilizá-los. Isso só acontecerá com a mudança de atitudes dos docentes.

\section{Critérios de avaliação nas escalas de desempenho}

Alguns professores entendem que os formatos de avaliação contêm os itens relacionados com os recursos afetivos, referindose à relação estudante-paciente, à comunicação verbal e não verbal, à ética, ao estado emocional 
do paciente e ressaltam o valor da observação do estudante (P2, P4, P23 e P22).

Outros professores apontam que os critérios existem, mas necessitam ser detalhados e clarificados em relação ao que se deve observar no estudante durante a avaliação, adequando-os ao tempo disponível (P1, P12 e P15). Mencionam que o formato apresenta critérios mais direcionados aos recursos psicomotores e cognitivos e menos aos afetivos (P23).

$\mathrm{Na}$ visão do estudante, o professor utiliza poucos critérios dos contidos na escala de desempenho para avaliá-los, como, por exemplo, o respeito e a atenção ao paciente. "São duas palavras para avaliar toda essa faixa de critério de afetividade" (EE 23).

Apesar de os formatos de avaliação conterem os critérios para avaliar os recursos afetivos, ainda alguns professores solicitam maior detalhamento e clarificação deles. O estudante também necessita detalhamento de aspectos relacionados à atitude para se sentir bem avaliado.

\section{Limites e potencialidades da avaliação dos recursos afetivos na percepção dos estudantes e professores}

No que se refere à avaliação dos recursos afetivos, no cenário simulado da prática profissional, tanto estudantes como professores destacam limites e potencialidades. O estudante EE12 menciona que o contato no LPP é mais próximo, o grupo é pequeno e pode ser melhor observado pelo professor nas atividades. Os professores P10 e P13 também entendem que o exercício de avaliação da prática profissional favorece a observação dos recursos afetivos.
Outros estudantes apontam limites na simulação. O EM33 considera que na vida real a pessoa tem mais oportunidade de demonstrar suas atitudes. O EE23 reitera essa opinião, acrescentando que o limite de tempo estabelecido no LPP prejudica o contato afetivo, o melhor tratamento, a conversa mais descontraída e leva o estudante a se preocupar mais com a tarefa. Essa visão do estudante pode estar relacionada ao reforço que é dado pelo professor para os recursos cognitivos e psicomotores, colocando os recursos afetivos em segundo plano, ou pela forma como tais recursos estão descritos na escala de desempenho.

O professor (P20) também destaca como limite a questão do pouco tempo destinado ao exercício simulado. Consideramos que, nos anos iniciais da formação do estudante, o tempo é um fator importante para que ele incorpore no seu desempenho a articulação dos recursos cognitivos, afetivos e psicomotores, para que, posteriormente, ele possa acessá-los em um tempo mais curto e em cenários diversificados da sua vida profissional.

Além disso, o EE41 considera que o nervosismo durante o LPP prejudica a empatia. Neste sentido, o LPP tem sido percebido pelo estudante como um momento de avaliação e de estresse e não como uma estratégia de ensino que favorece a aprendizagem de como lidar com estes sentimentos (COSTA et al., 2011).

Outro momento de geração de estresse é o feedback do professor e do grupo no final do exercício simulado. Quanto a isso, tem sido destacado por De Marco et al. (2010) a importância de estabelecer com o grupo um feedback construtivo, descritivo e não valorativo, 
reassegurando que o desempenho está adequado ao que se espera dele naquele momento.

O P7 destaca que a capacitação do paciente simulado é fundamental para a aproximação com situações da prática profissional e nem sempre esse está preparado para qualquer eventual pergunta, que pode estar fora do script, dificultando a avaliação do recurso afetivo.

\section{CONSIDERAÇÕES FINAIS}

Este estudo mostrou que professores e estudantes apresentam dificuldade na conceituação dos recursos afetivos. Eles reconhecem que existem critérios para se avaliarem esses recursos nos formatos de avaliação do EAPP. No entanto, sugerem que estes precisam ser mais claros, pactuados coletivamente e valorizados na capacitação docente. Considera-se que o espaço grupal e de aprendizagem cooperativa do LPP propicia o desenvolvimento dos recursos afetivos, por meio da avaliação e autoavaliação, o que favorece o aumento da percepção de si, com estratégias de superação para desenvolvê-los.

\section{REFERÊNCIAS}

BRAGA, E. M.; SILVA, M. J. P. Como especialistas em comunicação expressam a competência comunicativa. Interface Comun. Saúde Educ., Botucatu, v. 14, n. 34, p. 529-538, 2010.

CARNEIRO, L. A. et al. O ensino da ética nos cursos de graduação da área de saúde. Rev. Bras. Educ. Med., Rio de Janeiro, v. 34, n. 3, p. 412-421, 2010.

COLARES, M. F. A. et al. Construção de um instrumento para avaliação das atitudes de estudantes de medicina frente a aspectos relevantes da prática médica. Rev. Bras. Educ. Med., Rio de Janeiro, v. 26, n. 3, p. 194-203, set./dez. 2002
COSTA, M. C. G. et al. Exercício de avaliação da prática profissional como estratégia de ensino e aprendizagem. Avaliação, Campinas, v. 16, n. 3, p. 675-684, nov. 2011.

DE MARCO, M. A. et al. Laboratório de comunicação: ampliando as habilidades do estudante de medicina para a prática da entrevista. Interface

Comum. Saúde Educ., Botucatu, v. 14, n. 32, p. 217 227, jan./mar. 2010.

DE MARCO, M. A. et al. Comunicação, humanidades e humanização: a educação técnica, ética e estética e emocional do estudante e do profissional de saúde. Interface Comum. Saúde Educ., Botucatu, v. 17, n. 46, p. 683-693, jul./set. 2013.

FACULDADE DE MEDICINA DE MARÍLIA. Caderno de avaliação: cursos de medicina e enfermagem. Marília, 2015.

GOMES, R. A análise de dados em pesquisa qualitativa. In: MINAYO, M. C. S., (Org.). Pesquisa social: teoria, método e criatividade. 34 . ed. Petrópolis: Vozes, 2016. p.79-108.

MORAES, M. A. A. et al. O uso da simulação como estratégia avaliativa na graduação em saúde. In: MORAES, M. A. A. et al. (Org.). Avaliação nos cursos de medicina e enfermagem: perspectivas e desafios. Curitiba: CRV, 2012. p.143-161.

OLIVEIRA, V. T. D.; BATISTA, N. A. Avaliação formativa em sessão tutorial: concepções e dificuldades. Rev. Bras. Educ. Med., Rio de Janeiro, v. 36, n. 3, p. 374-380, 2012.

PAPINCZAK, T. et al. An analysis of peer, self, and tutor assessment in problem-based learning tutorials. Med. Teach., v. 29, n. 5, p. 122-132, Jun. 2007. Disponível em:

<http://informahealthcare.com/doi/pdf/10.1080/01421 590701294323>. Acesso em: 10 jun. 2018.

SANTIAGO, P. S. N.; CARVALHO, D. V. Habilidades afetivas na formação do profissional de enfermagem. REME, Belo Horizonte, v. 10, n. 3, p. 292-296, 2006.

SUARTZ, C. V. et al. Avaliação de empatia em residentes de especialidades clínicas e cirúrgicas da Universidade Federal de São Paulo. Rev. Bras. Educ. Med., Rio de Janeiro, v. 37, n. 3, p. 320-325, 2013.

TRONCON, L. E. A. et al. Atitudes de graduandos em medicina em relação a aspectos relevantes da prática médica. Rev. Bras. Educ. Med., Rio de Janeiro, v. 27, n. 1, p. 20-28, jan./abr. 2003. 


\begin{tabular}{l}
\hline Magali Aparecida Alves de Moraes \\
Psicóloga. Doutora em Educação. Docente da \\
Graduação e Pós-graduação da Famema. \\
\hline
\end{tabular}

Maria Cristina Guimaraes da Costa

Enfermeira. Mestre em Enfermagem em Saúde Pública. Docente da Graduação e preceptora do Programa de Residência Multiprofissional Materno Infantil da Famema.

Luzmarina Aparecida Doretto Braccialli

Enfermeira. Doutora em Ciências da Saúde. Docente

da Graduação e Pós-graduação da Famema.

\section{Cleber José Mazzoni}

Médico. Mestre em Educação na área da saúde.

Coordenador do Curso de Medicina da Famema. 